\title{
Efficacy of Salvage Therapy and Its Effect on Operative Outcomes in Patients with Ulcerative Colitis
}

\author{
Eiko Saito $^{\mathrm{a}}$ Masakazu Nagahori ${ }^{\mathrm{a}}$ Toshimitsu Fujii $^{\mathrm{a}}$ Kazuo Ohtsuka ${ }^{\mathrm{b}}$ \\ Mamoru Watanabe ${ }^{a}$ \\ Departments of a Gastroenterology and Hepatology and ${ }^{b}$ Endoscopy, Tokyo Medical and Dental University, \\ Tokyo, Japan
}

\section{Key Words}

Ulcerative colitis · Infliximab · Tacrolimus

\begin{abstract}
Aims: To evaluate the efficacy and safety of salvage therapy, and to identify risk factors of operative complications among hospitalized ulcerative colitis (UC) patients. Patients and Methods: We evaluated 88 UC patients hospitalized at our center between April 2010 and November 2012. We compared characteristics of corticosteroid-refractory patients treated with calcineurin inhibitor and those with infliximab as second-line therapy. Furthermore, we compared the characteristics of operative and nonoperative patients. The association between perioperative treatments and complications was also investigated. Results: Calcineurin inhibitor and infliximab were used in 42 and 22 patients, respectively. We found no difference in the clinical background between them. Efficacy rates were 67 and 50\%, respectively. Eight out of 10 nonresponders of each treatment were treated with the other drug as third-line therapy. The efficacy rates of calcineurin inhibitor and infliximab as the third-line therapy were 75 and $50 \%$, respectively. Operative patients had more severe disease ( 87.5 vs. $31 \%, p<0.01$ ), higher Lichtiger score (14.1 vs. $11.5, p<0.01$ ), higher Rachmilewitz endoscopic in-
\end{abstract}

\section{KARGER}

(c) 2014 S. Karger AG, Basel

0012-2823/14/0891-0055\$39.50/0

E-Mail karger@karger.com

www.karger.com/dig $\operatorname{dex}(10.5$ vs. 8.4, $\mathrm{p}<0.01$ ), higher C-reactive protein (7.6 vs. $4.0, p=0.015)$ and lower serum albumin (3.1 vs. $3.6, p=$ 0.014 ) than nonoperative patients. Complications were observed in 7 out of 16 (44\%) operative patients. Postoperative complications were not increased even when patients were treated with second- or third-line therapy. However, the complication rate in corticosteroid users was $54.5(6 / 11)$ and $20 \%(1 / 5)$ in nonusers. Conclusions: Third-line salvage therapy is effective and tolerable in carefully selected UC patients. Perioperative use of corticosteroids may lead to more adverse outcomes.

(c) 2014 S. Karger AG, Basel

\section{Introduction}

Treatment options for corticosteroid-refractory ulcerative colitis (UC) and the evidence for their efficacy have increased over the past decade [1]. Progress in medical treatment is also expected to decrease the operative rate of severe UC patients. Ogata et al. [2] reported that the calcineurin inhibitor, tacrolimus, was superior to placebo for achieving clinical response, clinical remission and mucosal healing in hospitalized patients with steroid-refractory UC. The efficacy of infliximab in UC was dem- 
Fig. 1. Efficacy results of medical treatment through second- and third-line therapies. Among 88 patients with steroid-refractory or dependent UC, 64 patients were treated with second-line therapy. Forty-two patients received calcineurin inhibitor and 22 patients received $5 \mathrm{mg} / \mathrm{kg}$ of infliximab. As the second-line therapy, calcineurin inhibitor was effective in $66.7 \%(28 / 42)$ of patients and infliximab was effective in 50\% $(11 / 22)$ of patients. As the third-line therapy, calcineurin inhibitor was effective in $75 \%(6 / 8)$ of patients and infliximab was effective in $50 \%(4 / 8)$ of patients.

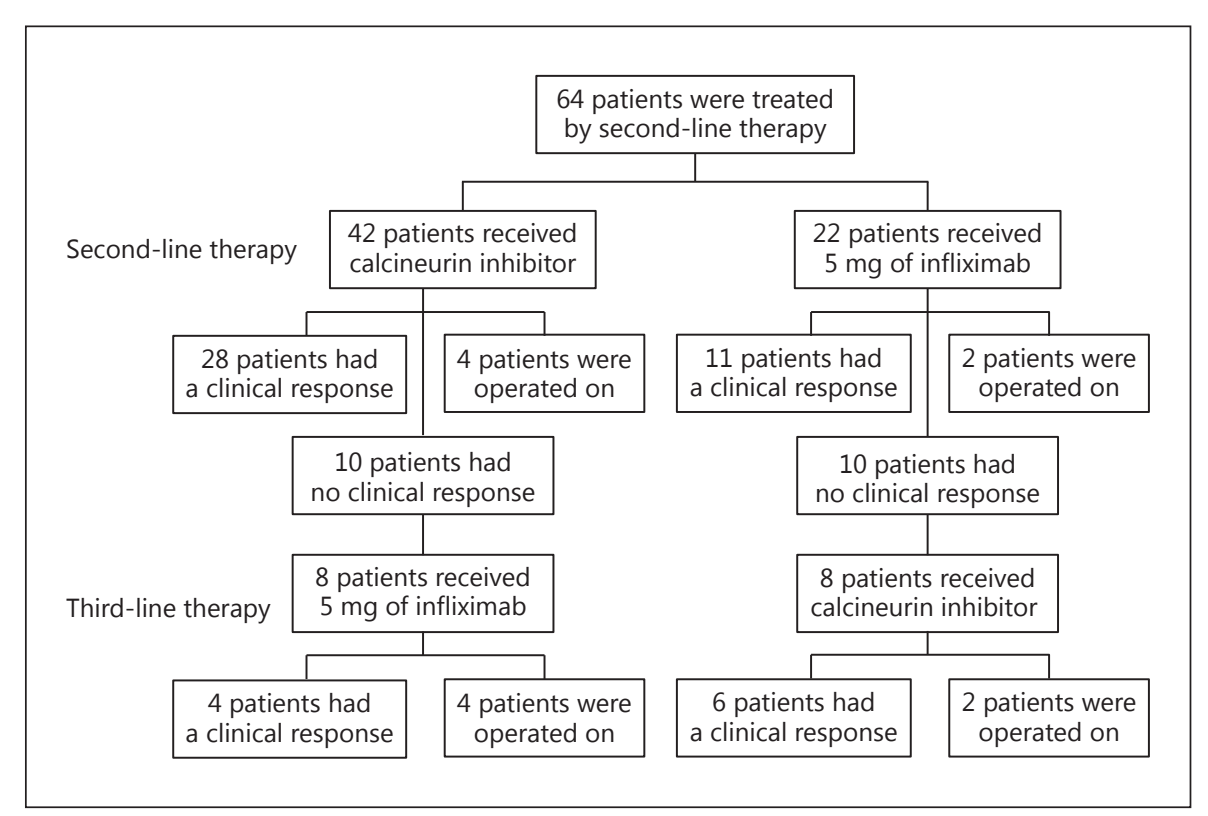

onstrated in two large clinical studies, the Active Ulcerative Colitis Trial (ACT)-1 and ACT-2. They showed that infliximab was superior to placebo for achieving clinical response, clinical remission and mucosal healing in patients with moderate-to-severe active UC despite treatment with concurrent medications [3].

The treatment selection among these therapeutic options, including cyclosporine, for each patient, and especially for corticosteroid-refractory patients, is uncertain. Furthermore, the risk factors of postoperative complications including perioperative medical treatment are not fully understood. We first compared the characteristics between patients treated with calcineurin inhibitor and those with infliximab to reveal factors associated with selection between these two medications. Then we compared the baseline features of operative and nonoperative patients. Finally, postoperative complications and their possible associations with preoperative medical treatment were investigated.

\section{Patients and Methods}

We retrospectively evaluated 88 patients with UC who were consecutively admitted to the Advanced Clinical Center for Inflammatory Bowel Diseases at the Tokyo Medical and Dental University Hospital between April 2010 and November 2012. When we defined steroid refractory as not responding to $1 \mathrm{mg} / \mathrm{kg}$ bodyweight of prednisolone or at least $30 \mathrm{mg}$ daily within 5-10 days, and steroid dependent as recurring during the reduction of corticosteroid dose or within 3 months of discontinuation, $83 \%(73 / 88)$ of the patients were corticosteroid refractory or dependent. Among them, calcineurin inhibitor or infliximab was required in $64 \mathrm{pa}-$ tients as the second-line therapy. We used cyclosporine or tacrolimus as a calcineurin inhibitor. Cyclosporine was initially administered at $2 \mathrm{mg} / \mathrm{kg} /$ day with an adjusted serum level of $200-400 \mathrm{ng} /$ $\mathrm{ml}$ for 10-14 days, after which it was switched to oral administration. At the time of initiation, tacrolimus was administered as a continuous infusion at a dose of $0.025 \mathrm{mg} / \mathrm{kg} / \mathrm{day}$ for 7 days, which was adjusted every $24-48 \mathrm{~h}$ to reach a therapeutic concentration of between 12 and $18 \mathrm{ng} / \mathrm{ml}$, followed by a switch to oral formula twice daily [4]. The dose was adjusted for its trough concentration to reach between 5 and $10 \mathrm{mg} / \mathrm{ml}$. Patients received infliximab at $5 \mathrm{mg} / \mathrm{kg}$ intravenously at weeks 0,2 and 6 . Those who achieved a response at week 10 received the same dose of infliximab every 8 weeks thereafter. Among those who did not respond to the secondline therapy, 8 in whom calcineurin inhibitor failed were treated subsequently with infliximab, and 8 patients who did not respond to infliximab were then treated with calcineurin inhibitor (fig. 1). We compared patients who were treated with calcineurin inhibitor to those who were treated with infliximab as the second-line therapy. The following parameters were evaluated: patient age, gender, disease type, severity, morbidity duration, Lichtiger clinical activity score [5], Rachmilewitz endoscopic index [6], C-reactive protein $(\mathrm{mg} / \mathrm{dl})$, hemoglobin $(\mathrm{g} / \mathrm{dl})$, albumin $(\mathrm{g} / \mathrm{dl})$ and duration of hospitalization. At our institution, the Lichtiger clinical activity score is recorded daily in all hospitalized UC patients, which enables us to evaluate the daily score in a retrospective manner. A response was defined as Lichtiger clinical activity score $<10$ and decrease $>4$, and clinical remission was defined as a score $\leq 4$ before discharge. However, in patients who achieved the response but required additional induction therapy, we also defined the therapy as nonresponse. Furthermore, we compared operative and nonoperative patients using the same parameters. Among the operative patients, we evaluated the perioperative medical treatments and complications. 
Table 1. Baseline characteristics of the patients $(n=88)$

\begin{tabular}{lc}
\hline Characteristic & \\
\hline Age, years & $41.8 \pm 17.9(17-86)$ \\
Gender & $54(61)$ \\
$\quad$ Male & $34(39)$ \\
$\quad$ Female & $70(80)$ \\
Disease extent & $18(20)$ \\
$\quad$ Total colitis & \\
Left-sided colitis & $36(41)$ \\
Severity & $52(59)$ \\
$\quad$ Severe & $5.6 \pm 6.8(0-30)$ \\
$\quad$ Moderate & $12 \pm 3(5-20)$ \\
Duration of disease, years & $8.8 \pm 2.1(4-12)$ \\
Lichtiger score & $4.68 \pm 5.33(0.03-23.93)$ \\
Rachmilewitz endoscopic index & $11.8 \pm 2.3(6.8-18.5)$ \\
C-reactive protein, mg/dl & $3.5 \pm 0.7(1.7-4.8)$ \\
Hemoglobin, g/dl & \\
Albumin, g/dl & \\
Concurrent medication & \\
$\quad$ Corticosteroid & Dependent \\
$\quad$ Refractory & $45(32)$ \\
6-Mercaptoprine/azathioprine & $38(43)$ \\
\hline
\end{tabular}

Values are either means $\pm \mathrm{SD}$ with ranges in parentheses, or numbers with percentages in parentheses.

\section{Statistics}

Quantitative data are given as mean and standard deviation. Categorical variables were compared using the $\chi^{2}$ test or Fisher's exact test (two-tailed), whichever was appropriate. Continuous variables were compared using Student's t test or Mann-Whitney $\mathrm{U}$ test, depending on the distribution. A p value $<0.05$ was considered as significant.

\section{Results}

The mean age of the 88 patients was $42(17-86)$ years. The gender distribution was 54 males and 34 females. With regard to the disease extent, $80 \%(70 / 88)$ of patients had total colitis while $20 \%(18 / 88)$ had left-sided colitis. Thirty-six patients had severe disease activity, and $52 \mathrm{pa}$ tients had moderate disease activity. The mean morbidity duration was 6 (0-30) years. The mean Lichtiger clinical activity score was 12 (5-20), Rachmilewitz endoscopic index was 9 (4-12), C-reactive protein level was 4.7 (0.0323.93) $\mathrm{mg} / \mathrm{dl}$, hemoglobin level was $12(7-19) \mathrm{g} / \mathrm{dl}$ and serum albumin level was $3.5(1.7-4.8) \mathrm{g} / \mathrm{dl}$ (table 1$)$. The background characteristics of patients who were treated with calcineurin inhibitor and those with infliximab as

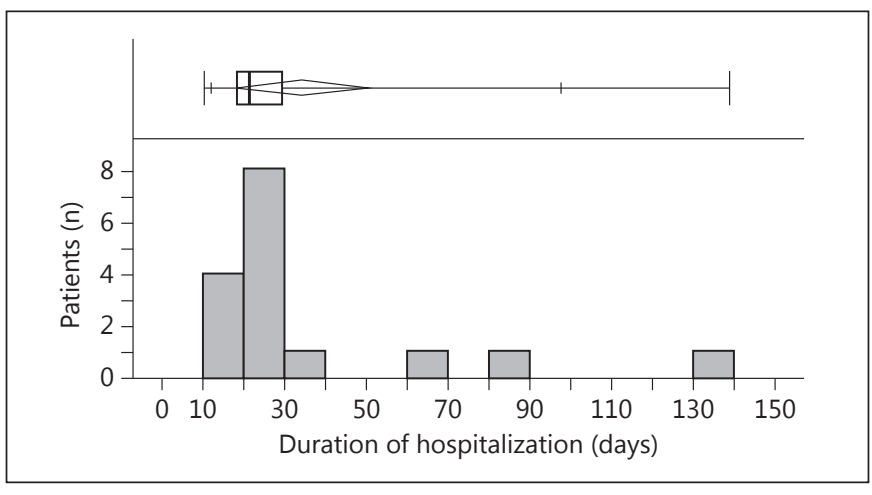

Fig. 2. Duration of hospitalization after operation. Most of the operative patients were discharged within 30 days [median 21.5 days (10-139)].

the second-line therapy were not significantly different. With regard to the efficacy of second-line therapy, $67 \%$ $(28 / 42)$ of patients who were treated with calcineurin inhibitor and 50\% (11/22) of those who were treated with infliximab showed response. Regarding the efficacy of third-line therapy, $75 \%(6 / 8)$ of patients who were treated with calcineurin inhibitor and 50\% (4/8) of those who were treated with infliximab showed response.

We compared operative and nonoperative patients using the same parameters (table 2). No differences were observed in age, disease type, morbidity duration and previous medication between the two groups. However, we found that operative patients as compared to nonoperative patients included more males ( 87.5 vs. $56 \%, \mathrm{p}=$ 0.018 ), had more severe disease activity ( 87.5 vs. $31 \%, \mathrm{p}<$ 0.01 ), had a higher mean Lichtiger score (14.1 vs. 11.5, $\mathrm{p}=0.003)$, a higher mean Rachmilewitz endoscopic index (10.5 vs. 8.4, $\mathrm{p}=0.001)$, a higher mean C-reactive protein level (7.6 vs. $4.0 \mathrm{mg} / \mathrm{dl}, \mathrm{p}=0.0015)$ and a lower mean albumin level (3.1 vs. $3.6 \mathrm{~g} / \mathrm{dl}, \mathrm{p}=0.014)$.

Among the operative patients $(n=16)$, the mean duration of hospitalization after surgery was 33.9 (10-139) days (fig. 2). Perioperative complications were observed in 7 patients $(43.8 \%)$. The complications included two bleeding, one infection, one persistent pyrexia, one anemia, one low nutrition and one ileus. Reoperation was not needed and no deaths were observed. Three medical treatment patterns were used in the patients before operation. In pattern 1 , only one medication among corticosteroid, calcineurin inhibitor and infliximab was used preoperatively. In pattern 2 , two medications out of the above three were used. In pattern 3 , all of the above three medications were used. Among the 7 patients with com- 
Table 2. Characteristics of the operated and nonoperated patients

\begin{tabular}{lccc}
\hline Characteristic & Operated $(\mathrm{n}=16)$ & Nonoperated $(\mathrm{n}=72)$ & $\mathrm{p}$ \\
\hline Age, years & $41.8 \pm 22.2(18-78)$ & $41.8 \pm 17.0(17-86)$ & 0.795 \\
Gender & & & 0.018 \\
$\quad$ Male & $14(87.5)$ & $40(56)$ & \\
$\quad$ Female & $2(12.5)$ & $32(44)$ & 0.852 \\
Disease extent & $13(81)$ & $57(79)$ & \\
$\quad$ Total & $3(19)$ & $15(21)$ & $<0.01$ \\
$\quad$ Left-sided & $14(87.5)$ & $22(31)$ & 0.308 \\
Severity & $2(12.5)$ & $50(69)$ & 0.003 \\
$\quad$ Severe & $4 \pm 6(0.1-25)$ & $5.9 \pm 7(0-30)$ & 0.001 \\
$\quad$ Moderate & $14.1 \pm 3.5(5-20)$ & $11.5 \pm 2.9(5-19)$ & 0.015 \\
Duration of disease, years & $10.5 \pm 1.4(8-12)$ & $8.4 \pm 2.1(4-12)$ & 0.214 \\
Lichtiger score & $7.6 \pm 6.6(1.02-23.98)$ & $4.0 \pm 4.8(0.03-21.5)$ & 0.014 \\
Rachmilewitz endoscopic index & $11.1 \pm 1.9(8.4-16.3)$ & $11.9 \pm 2.4(6.8-18.5)$ & \\
C-reactive protein, mg/dl & $3.1 \pm 0.8(1.9-4.3)$ & $3.6 \pm 0.7(1.7-4.8)$ & 0.460 \\
Hemoglobin, g/dl & $5(31.3)$ & $25(34.7)$ & 0.543 \\
Albumin, g/dl & $11(68.7)$ & $32(44.3)$ & $30(42)$ \\
Corticosteroid & $8(50)$ & & \\
$\quad$ Dependent & & & \\
$\quad$ Refractory & & & \\
Concurrent immunomodulator & & & \\
\hline
\end{tabular}

Values are either means \pm SD with ranges in parentheses, or numbers with percentages in parentheses. $p$ values for all categorical variables are based on a two-sided $\chi^{2}$ test.

plications, 2, 4 and 1 were categorized into patterns 1,2 and 3, respectively. Among the 9 patients without complications, 4, 2 and 3 were categorized into patterns 1, 2 and 3, respectively. Even when the number of medications used increased, it appeared that the complication rate did not necessarily increase. The complication rates in patients who were treated with corticosteroid, calcineurin inhibitor and infliximab were 54.5 (6/11), 33.3 $(3 / 9)$ and $25 \%(2 / 8)$, respectively.

\section{Discussion}

In recent years, medical treatment of UC has improved, and calcineurin inhibitor and infliximab are established treatment options for corticosteroid-refractory UC patients $[2,3,7]$. However, the standard selection criteria for medications in moderate-to-severe corticosteroid-refractory UC patients as well as the decision to discontinue medical treatment to advance to operation are not well delineated. It is also unclear whether certain medical treatments may affect the operative prognosis or not. To gain insight into the selection between cyclosporine and infliximab, an open-label randomized controlled trial was conducted at
27 European centers [8]. The study reported that the efficacy of cyclosporine and infliximab was comparable. In our present study, we retrospectively compared the clinical backgrounds of patients who were treated with calcineurin inhibitor with those who were treated with infliximab, to elucidate the possible factors which may have positively contributed to our treatment selection in moderate-to-severe UC patients. The efficacy of treatment after refractory/ dependent corticosteroid therapy with calcineurin inhibitor and infliximab was $66.7(28 / 42)$ and 50\% (11/23), respectively $(p=0.19)$. We found no differences in the clinical background and efficacy between the two groups. In summary, we think that calcineurin inhibitor and infliximab are equivalent as salvage therapy in corticosteroidrefractory UC patients. Furthermore, we administered infliximab to 8 calcineurin inhibitor nonresponders, and also gave calcineurin inhibitor to 8 cases who did not respond to infliximab. The efficacy of calcineurin inhibitor and infliximab as salvage therapy was $75(6 / 8)$ and $50 \%(4 / 8)$, respectively $(p=0.30)$. Several studies have reported on the efficacy and safety of infliximab as a rescue therapy for UC refractory to calcineurin inhibitor [9-12]. In each study, infliximab was deemed a successful rescue therapeutic option in patients with UC refractory to calcineurin inhibitor. 
In these situations, infectious complications could be fatal, although no serious adverse events occurred in our series. In the study conducted by Maser et al. [13], the efficacy and safety of cyclosporine and infliximab as rescue therapy for each other in patients with corticosteroid-refractory UC were assessed. In their study, the remission rates using acute salvage therapy by crossing over to the other drug was approximately one third of patients, but serious adverse events occurred in $16 \%$ of patients, including 1 death.

We compared operative and nonoperative patients to reveal factors that may aid in identification of potential nonresponders to medical therapy. Several risk scores have been developed to predict outcomes of medical treatment in severe UC. One of them is the 'Ho index', which is formulated on three variables, mean stool frequency, colonic dilatation and hypoalbuminemia [14]. Because all of these variables reflect severe disease activity, our results showing that patients who underwent surgery had more severe disease, higher Lichtiger score, higher Rachmilewitz endoscopic index, higher C-reactive protein level and lower serum albumin level are compatible with the previous findings, although the reason why more operative patients were male is unknown.

We also investigated the operative prognosis of patients who needed operation after rescue therapy. Sixteen out of 42 patients who received rescue therapy underwent operation. The median duration of hospitalization after operation was 21.5 days. The association between the number of preoperative immunosuppressive treatments used and rate of postoperative complications is unclear. However, the postoperative complication rate in patients who were treated with corticosteroid before surgery was as high as $54.5 \%(6 / 11)$. As previous studies reported, it is suggested that corticosteroid use is one of the risk factors for operative infectious complications in patients with inflammatory bowel disease who undergo bowel surgery $[15,16]$. It is well recognized that rescue therapy by calcineurin inhibitor and infliximab is effective and tolerated. In our study, salvage therapy with these drugs was successful in short-term efficacy and prevention of operation in $81.8 \%$ of patients with corticosteroid-refractory/dependent UC. Moreover, no serious adverse events occurred. However, 3 of the operative patients needed to be hospitalized for a long duration due to complications (fig. 2).

There are several limitations to our current study, including a small sample size. The risk of complications after operation needs to be evaluated in a larger group of patients. Because the choice of rescue therapy was decided by clinicians on an individual basis, it is probable that patients who were considered to be at risk of developing complications were carefully excluded from rescue therapy and had undergone surgery instead. Consequently, the efficacy and relatively good safety profile of rescue therapy in our study patients cannot be generalized to all refractory UC patients. Recently, Coakley et al. [17] reported an association between prolonged medical treatment and poor postoperative outcomes in fulminant UC patients. Thus, it is crucial to identify and carefully select for UC patients who will benefit from rescue therapy especially with regard to efficacy and safety.

\section{Conclusions}

Calcineurin inhibitor and infliximab may be successful therapeutic options as third-line salvage therapy in corticosteroid-refractory/dependent UC patients who did not respond to the other drug. Although in our study complications were not increased after third-line salvage therapy, immunosuppressive medications are theoretically associated with an increased risk of postoperative infectious complications, particularly surgical site infections. Our findings suggest that perioperative use of corticosteroid may play a role in more adverse outcomes. However, we believe that third-line salvage therapy in carefully selected patients is effective and tolerable for treatment of moderate-to-severe corticosteroid-refractory/dependent UC.

\section{Disclosure Statement}

The authors have no conflicts of interest to declare.

References

Manz M, Vavricka SR, Wanner R, Lakatos PL, Rogler G, Frei P, Safroneeva E, Schoepfer AM: Therapy of steroid-resistant inflammatory bowel disease. Digestion 2012;86(suppl 1): 1-15.

- Ogata H, Kato J, Hirai F, Hida N, Matsui T, Matsumoto T, Koyanagi K, Hibi T: Doubleblind, placebo-controlled trial of oral tacrolimus (FK506) in the management of hospitalized patients with steroid-refractory ulcerative colitis. Inflamm Bowel Dis 2012;18: 803-808.

-3 Rutgeerts P, Sandborn WJ, Feagan BG, Reinisch W, Olson A, Johanns J, Travers S, Rachmilewitz D, Hanauer SB, Lichtenstein GR, Villiers WJS, Present D, Sands BE, Colombel JF: Infliximab for induction and maintenance therapy for ulcerative colitis. N Engl J Med 2005;353:2462-2476.
Salvage Therapy and Its Effect on

Operative Outcomes in Patients with UC
DOI: 10.1159/000356221 
4 Naganuma M, Fujii T, Watanabe M: The use of traditional and newer calcineurin inhibitors in inflammatory bowel disease. J Gastroenterol 2011;46:129-137.

5 Lichtiger S, Present DH, Kornbluth A, Gelernt I, Bauer J, Galler G, Michelassi F, Hanauer S: Cyclosporine in severe ulcerative colitis refractory to steroid therapy. N Engl J Med 1994;330:1841-1845.

6 Rachmilewitz D: Coated mesalazine (5-aminosalicylic acid) versus sulphasalazine in the treatment of active ulcerative colitis: a randomized trial. BMJ 1989;298:82-86.

7 Schmidt KJ, Herrlinger KR, Emmrich J, Barthel D, Koc H, Lehnert H, Stange EF, Fellermann K: Short-term efficacy of tacrolimus in steroid-refractory ulcerative colitis-experience in 130 patients. Aliment Pharmacol Ther 2013;37:129-136.

$\checkmark 8$ Laharie D, Bourreille A, Branche J, Allez M, Bouhnik Y, Filippi J, Zerbib F, Savoye G, Nachury M, Moreau J, Delchier JC, Cosnes J, Ricart E, Dewit O, Lopez-Sanroman A, Dupas JL, Carbonnel F, Bommelaer G, Coffin B, Roblin X, Assche GV, Esteve M, et al: Cicrosporin versus infliximab in patients with severe ulcerative colitis refractory to intravenous steroids: a parallel, open-label randomized controlled trial. Lancet 2012;380:1909-1915.
\9 Mañosa M, López San Román A, GarciaPlanella E, Bastida G, Hinojosa J, GonzalezLama YG, Masnou H, Domenech E: Infliximab rescue therapy after cyclosporin failure in steroid-refractory ulcerative colitis. Digestion 2009;80:30-35.

10 Yamamoto S, Nakase H, Matsuura M, Honzawa Y, Matsuda S, Inui K, Chiba T: Efficacy and safety of infliximab as rescue therapy for ulcerative colitis refractory to tacrolimus. J Gastroenterol Hepatol 2010;25:886-891.

- 11 Herrlinger KR, Barthel DN, Schmidt KJ, Büning J, Barthel CS, Wehkamp J, Stange EF, Fellermann K: Infliximab as rescue medication for patients with severe ulcerative/indeterminate colitis refractory to tacrolimus. Aliment Pharmacol Ther 2010;31:1036-1041.

12 Leblanc S, Allez M, Seksik P, Flourie B, Peeters H, Dupas JL, Bouguen G, Peyrin-Biroulet L, Duclos B, Bourreille A, Dewit O, Bouhnik Y, Michetti P, Chaussade S, Saussure P, Mary JY, Colombel JF, Lemann M: Successive treatment with cyclosporine and infliximab in steroid-refractory ulcerative colitis. Am J Gastroenterol 2011;106:771-777.
13 Maser EA, Deconda D, Lichtiger S, Ullman T, Present DH, Kornbluth A: Cyclosporine and infliximab as rescue therapy for each other in patients with steroid-refractory ulcerative colitis. Clin Gastroenterol Hepatol 2008;6: 1112-1116.

14 Ho GT, Mowat C, Goddard CJ, Fennell JM, Shah NB, Prescott RJ, Satsangi J: Predicting the outcome of severe ulcerative colitis: development of a novel risk score to aid early selection of patients for second-line medical therapy or surgery. Aliment Pharmacol Ther 2004;19:1079-1087.

15 Aberra FN, Lewis JD, Hass D, Rombeau JL, Osborne B, Lichtenstein GR: Corticosteroids and immunomodulators: postoperative infectious complication risk in inflammatory bowel disease patients. Gastroenterology 2003; 125:320-327.

16 Uchino M, Ikeuchi H, Matsuoka H, Tsuchida $\mathrm{T}$, Tomita N, Takesue Y: Risk factor associated with surgical site infection after ileal pouch-anal anastomosis in ulcerative colitis. Dis Colon Rectum 2010;53:143-149.

17 Coakley BA, Telem D, Nguyen S, Dallas K, Divino CM: Prolonged preoperative hospitalization correlates with worse outcomes after colectomy for acute fulminant ulcerative colitis. Surgery 2013;153:242-248. 